\title{
On the Design of College English Precision Teaching Pattern Based on the Information Technology
}

\author{
*Zhongwen Liu \\ Liaoning Police Academy, Dalian, China
}

\begin{abstract}
The precision teaching is a teaching method based on Skinner's Behavioral Learning theory with the emphasis of tracing the students' learning performance through designing measured process in order to make data-based decisions about teaching goals and teaching strategies. With the information technology more and more integrated into the educational circles, the precision teaching displays many modern features. The paper analyzes the college English precision teaching concept and pattern which integrates its original teaching theories and practice into our traditional college English teaching. It mainly involves the establishment of college English skills tree and test library, the process design of developing intelligent multi-teaching materials, the creative methods to improve college English precise teaching, the counting and drawing learning performance chart by means of information technology. This precision teaching pattern can help English teachers focus on teaching design and individual intervention and service, making the students obtain highquality learning service and achieving higher learning goals consequently.
\end{abstract}

Keywords: The precision teaching, information technology, college English precision teaching pattern

\section{Introduction}

Precision Teaching, as the international educational term, refers to classroom teaching with precision teaching concept and concrete practice. In the early precision teaching practice, teachers and students had to record the students' performance with pencils to mark one point each time in teaching process, and make manmade analysis and decision accordingly. Although it has been a convenient means to supervise and control the students' performance for several decades, this teaching pattern is left out by the educators and teachers due to the lack of information technology in precision teaching under the tendency of education reform driven by educational information.

In view of the dim future of precision teaching, the paper focuses on the tentative introduction of information technology into the practice of college English precision teaching, designing the college English precision teaching pattern supported by information technology in order to activate the vitality of precision teaching in Chinese classrooms. This effective teaching pattern, on one hand, enables teachers to focus on teaching design and personalized intervention, and on the other hand, makes students obtain high-quality learning service. The goal of the research is to provide precision teaching service on the premise that we teachers carry on college English precision teaching aimed at problem teaching.

\section{Retrospection of Precision Teaching: Origin and Logical Relationship of Different Elements in Precision Teaching}

\subsection{The origin of precision teaching}

The precision teaching is a method put forward by Ogden Lindsley in the 60 s of $20^{\text {th }}$ century who based on Skinner's Behavioral Learning Theory. In the initial phrase, it was aimed at designing the measured process to trace the pupils' learning performance and support the data decision. Later, it was evolved into the framework to assess the validity of arbitrarily-given teaching methods. The precision teaching is able to assess any subject and any teaching in any phase of studying thanks to its being compatible with various teaching strategies.

\subsection{The logical relationship of different elements to guarantee the effective practice of precision teaching}

The precision teaching formulates different indicators to measure the students' learning development including fluency, accuracy, speed, and frequency. The real mastery of knowledge and skill not only consists in the learning quality and accuracy, but also in learning speed. Here, fluency implies accuracy plus speed. [1] At the same time, the establishment of frequency is the key link of ensuring fluency. Generally speaking, fluency includes five attributes: maintenance, endurance, stability, application, and generativity. [2] Maintenance requires students' abilities in carrying out the future tasks according to the demands but without additional 
exercises; endurance requires the abilities in long-term working hours to meet the real needs; stability requires the abilities in continuing one skill under the disturbed circumstance; application requires the abilities in easily applying the knowledge or skill in the new situation; generativity requires the abilities in performing complex behavioral skills without obvious guide. [3] Fig. 1 describes the detailed logical relationship of different elements in normal precision teaching.

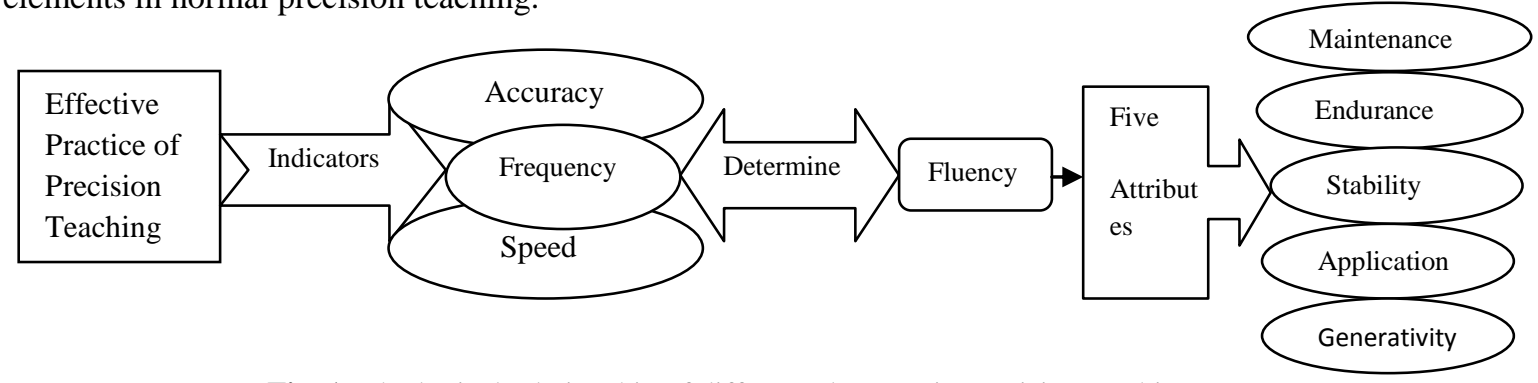

Fig. 1: The logical relationship of different elements in precision teaching

In addition, the precision teaching advocates the principle of Learners Know Best which means that learners' behavior can reflect the effectiveness of teaching much better than other approaches. [4] As a result, the precision teaching measures the frequency of learning behavior, stressing learning initiative. According to the frequency data, the precision teaching assists in judging the effectiveness of teaching approaches, and hence it is a precise method of data decision.

\section{Design of College English Precision Teaching Pattern Based on Information Technology 3.1 The framework design of college English precision teaching supported by IT}

In essence, the precision teaching isn't a concrete teaching method, but rather a method to assess teaching strategy and curriculum precisely and systematically. In order to promote the popular use of this modern and effective teaching concept and strategy, it's of necessity to construct a standard and operational teaching pattern to take great advantage of it.

Owing to the higher requirements of the precision teaching in mathematics and computer science, we have to lower the degree of difficulty in the design and practice of college English precision teaching. What we absorb from the precision teaching is to use its concept and scientific method for reference in English teaching. The ordinary precision teaching pattern supported by information technology is composed of four links: setting precise goals, developing teaching materials and teaching process, counting and drawing performance, and data decision-making. When setting goals, recursive idea is adopted. On developing teaching materials, it is vital to expand traditional learning materials to study materials, exercise materials, and creation materials which are called intelligent learning materials to emphasize the learners' creativity training. In the teaching process, the intelligent learning ecosystem is advocated, from differential teaching, group cooperative learning, and individual self-adjusted learning to group interactive and generative learning. As to counting and drawing performance, the counter and chart drawing tools based on Web can be used to draw the learners' performance. In the last step of decision-making, the analytical software can help us draw the accurate and analyze shift cables to judge whether the current teaching can accomplish the teaching goals expectably.

\subsection{The precise design of college English precision teaching pattern}

The establishment of college English skills tree and test library: according to features and natures of English knowledge and skills in different units, we should form the knowledge and skill tree through decomposing knowledge layer by layer. That is to say, on the knowledge and skills tree, we set the general goal and subgoals. Then we'll design different tests aimed at different subgoals which form test library to test the corresponding knowledge and skills. Here, the students' disadvantages should be mentioned, and only after successfully passing those tests testing their short slabs, the students can enter into the higher level of test library. If we can orientate the students' short slabs in knowledge and skill precisely, we'll draw a target tree to specialize in improving their weaknesses.

The precise process of developing intelligent teaching materials: after setting precise teaching goals for different units, the next task is to develop learning materials quite superior to those traditional teaching and learning materials. In the era of information, learning materials have been expanded greatly. Study materials, exercise materials, and creation materials all come into our views with great vitality and practicability. In recent years, micro-video has been applied into educational field applauded by teachers and students on account of its small capacity, short time span, self-sufficiency, easy communication, versatility, and reusability. [5] On the basis of micro-video, the micro lecture, the flipped classroom, and the MOOCs are widely used in college English Class. We select Unit 6: A Valentine Story as an example of the flipped classroom, and the followed fig. 
2 displays the main topics for group discussion and some warm-up questions. Fig. 3 is the PPT display of the micro lecture: How to describe personality through emotional reactions?

\section{Group Discussion}
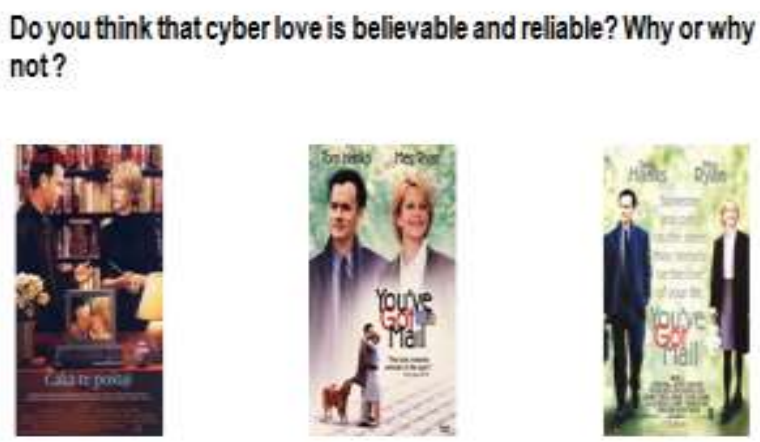

Fig. 2: The main topics for group discussion and warm-up questions for Unit 6: A Valentine Story in flipped classroom

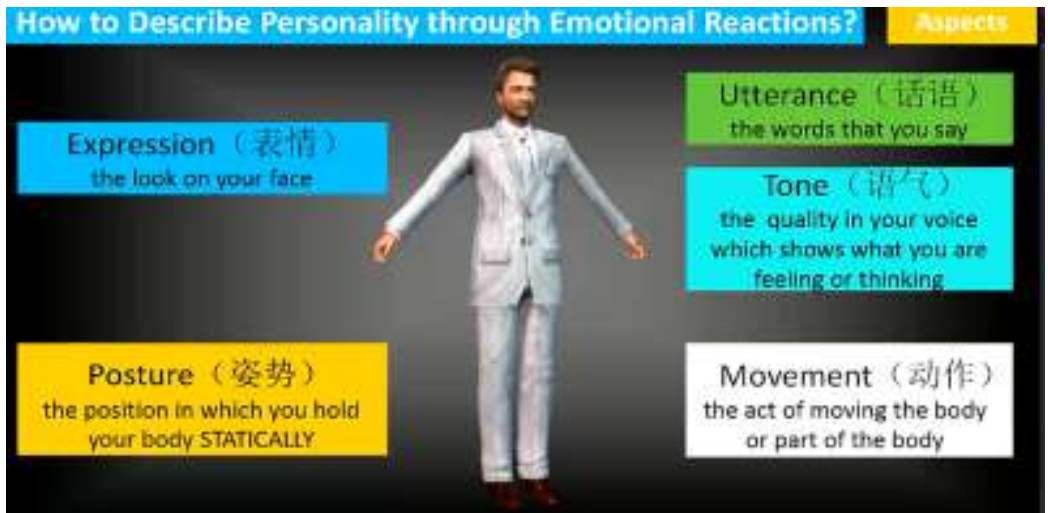

Fig.3: The PPT design of micro lecture: How to describe personality through emotional reactions

The creative methods to improve precise college English teaching: the precison teaching strategy can be integrated into the current English teaching approach, such as directe teaching approach, the flipped classroom, the situated language teaching, the case teaching method, and so on. We also depend on the support of the information technology to develop intelligent learning method. The intelligent leanring method is seperated into four creative teaching and learning methods which are differnetial teaching, group cooperative and creative learning, individual self-adjusted learning, and group interactive and generative learning. Fig. 4 is an exmaple of cooperative and creative learning in the English class of Liaoning Police Academy. The differential teaching mainly carries on the task of mastering the fundamental knowledge and the core skill. The group cooperative and creative leanring focuses on training the comprehensive applied capability. The individual self-adjusted leanring stresses the training of individual specialty and capability. The group interactive and generative learning highlights the widely-connected generative learning in social communication. It is just because of so many definite and indefinite teaching goals that require English teachers to apply different teaching and learning methods in suitable teaching process. For example, the first two teaching methods can be applied into classroom precision teaching, and the latter ones can be applied in the hybrid learning space including online and offline learning space. Information technology with big data and seamless connection can help English teachers fullfill the tasks of precise analysis of the studnets' performance, learning curve graph, learning demands and effective teaching approach.

The counting and drawing learning performance chart by means of informaiton technology: The first and formost feature of precision teaching is reflected in this point. The precision lies in the precise recording data day by day in order to grasp the first-hand information of the studnts learning perfomance so as to set definite and precise goals for different class and student. Most of English precision teachers draw the standard celeration chart with students' one-minute test samples. This information chart can be finished by specialized chart tool Easy Charter or Aim Chart based on Web. College English teachers can master the basic skill in drawing chart with simple exercise. According to this standard chart, the precision teachers can supervise and record the studnets' short-term learning performance in order to master their developing process including 
progress and retrogress. The precise recording of students' performance determines precise data-based decision making. The last process of college English precision teaching is to set the definite and proper leanring goals suitable for specific students. Besides, this learning goal can be adjusted according to the actual completion.

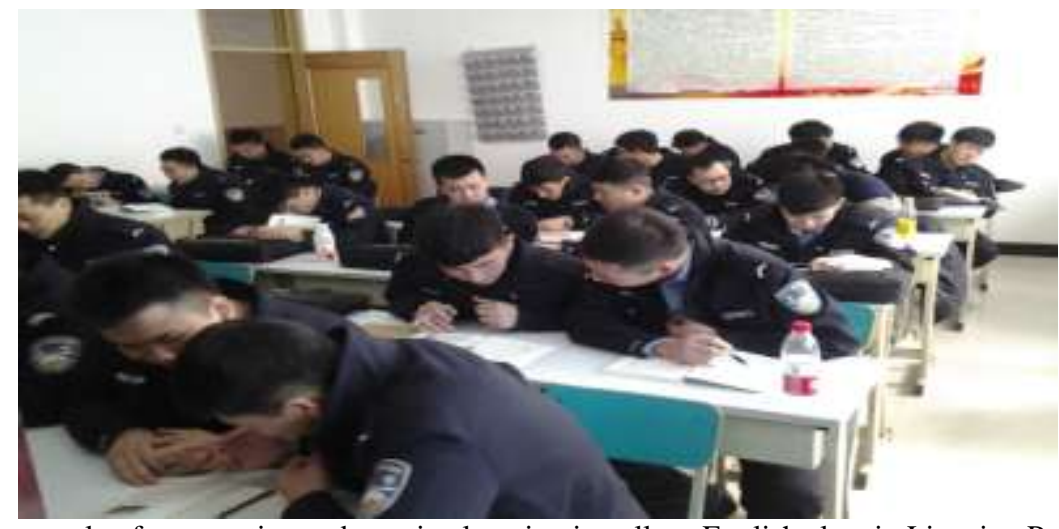

Fig. 4: An example of cooperative and creative learning in college English class in Liaoning Police Academy

The data-based decision making can not only analyze the students' performance frequency, but also help precision teachers to solve other complex problems. The precise learning demands can be obtained through big data mining and analysis. To find the potential learning problems and predict future performance is the maximum benefit from this scientific and precise teaching strategy. The college English precision teaching under the support of learning analytics and machine leanring can provide the students with the precise learning strategy, and the individual learning service as well. The differential teaching pattern and personalized service can be fulfilled in the mean time through precison teaching.

\section{Conclusion}

The college English precision teaching breaks the traditional teaching concept and pattern, introducing the standard celebration chart, frequency aim, multi-learning materials, short slab teaching, and machine learning into college English teaching practice. At present, this precision teaching, as one intelligent teaching technique, contributes to the development of precision mastery of knowledge and skills, and precise decision making of teaching goals and patterns. The information-based precision teaching can undoubtedly bring about the enormous progress in college English regular teaching and learning.

\section{Acknowledgements}

The research is financed by the Thirteenth Five-year Plan for Educational Science Project of Liaoning Province (2016) No.JG16DB213: A Study on Standard Model of FCM of EGP with Chinese Cultural Specialty, and by the Teaching Research Project of Liaoning Police Academy (2016) No.16LJY004: The Applied Study of Micro-video and Precision Teaching in College English Flipped Classroom.

\section{References}

[1] Binder, C. Precision teaching: Measuring and attaining exemplary academic achievement. Youth Policy, 10 (7), 1998, 12-15

[2] Johnson, K., Street, E. M. From the laboratory to the field and back again: Morningside Academy's 32 years of improving students' academic performance. The Behavior Analyst Today, 13(1), 2012, 20-40.

[3] Zhu Zhiting, Peng Hongchao. Technology Enabled Efficient Teaching of Knowledge: Activating the power of precision instruction. China Educational Technology, (1), 2016, 18-25.

[4] West, R. P. Precision teaching: an introduction. Teaching Exceptional Children. 22 (3), 1990, 4-9.

[5] Liu Mingzhuo, Zhu Zhiting. The design analysis and model building of micro lecture. China Educational Technology, (12), 2013, 127-131. 